\title{
A multidisciplinary simulation programme to improve advance care planning skills and engagement across primary and secondary care
}

\author{
Authors: Lucy Owen, ${ }^{A}$ Anna Steel, ${ }^{B}$ Kristin Goffe, ${ }^{A}$ Joanna Pleming ${ }^{C}$ and Elizabeth L Sampson ${ }^{D}$
}

\section{Background}

In the context of an ageing population, many healthcare professionals have limited experience and confidence in having necessary advance care planning (ACP) conversations.

Methods

We conducted nine half-day simulation sessions, using professional actors. One-hundred and thirty-two participants attended from multidisciplinary backgrounds across primary and secondary care.

Results

Following the course, $\mathbf{9 0 . 2 \%}$ felt confident or very confident initiating conversations, compared with $14.4 \%$ beforehand. Understanding of when ACP is appropriate also increased from $70 \%$ to $100 \%$. Post-course, $98 \%$ of participants stated that they would be more likely to initiate an ACP. Three months later, $86 \%$ had a sustained change in practice. All participants said they would recommend this simulation course and multidisciplinary approach.

\section{Conclusion}

Multidisciplinary simulation training is an effective way to teach ACP to doctors, nurses and allied healthcare professionals. The simulation was shown to improve participant understanding, confidence and reduce barriers to discussions, both immediately and 3 months later.

KEYWORDS: palliative care, advance care planning, frailty, multidisciplinary, simulation teaching

DOI: $10.7861 /$ clinmed.2021-0240

\section{Introduction}

Mortality trends suggest that 160,000 more people in England and Wales will need palliative care by $2040{ }^{1}$ Many of these

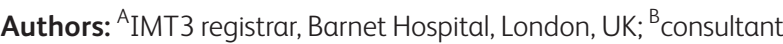
physician and geriatrician, Barnet Hospital, London, UK; 'ST8 registrar in geriatrics, stroke and general internal medicine, Barnet

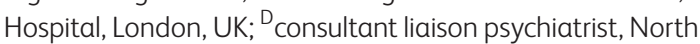
Middlesex University Hospital, London, UK and clinical professor in dementia and palliative care, University College London, London, UK patients will have complex, unpredictable disease courses with three-quarters of deaths in England following chronic illness currently. ${ }^{2}$ Numbers dying with dementia are also predicted to increase from 59,199 in 2014 to 219,409 in 2040. ${ }^{1}$ Rising needs mean that palliative care cannot be delivered by specialists alone. $^{3}$

In a European survey, $89.5 \%$ of 9,344 respondents valued knowing about care options. ${ }^{4}$ Advance care planning (ACP) is a series of conversations with a patient, or nominated representative, eliciting an individual's wishes and healthcare preferences that take effect should they lose capacity. ${ }^{5-7}$

Where wishes are not explored with patients and their loved ones, proxy decision makers are more likely to opt for aggressive treatments at a time of crisis, which may lead to unwanted outcomes and worsen bereavement reactions. ${ }^{3,5}$ Quality ACP improves patient satisfaction together with reducing transfers between care settings. ${ }^{3,5}$ Where a conversation has taken place detailing where someone would like to die, the person was almost twice as likely to die in that place. ${ }^{5}$ Those who died outside of hospital had a lower mean treatment cost. ${ }^{8}$

Patients expect medical professionals to initiate ACP conversations and will rarely do so themselves. ${ }^{9}$ Yet more than half of physicians feel unprepared through a lack of confidence, uncertainty of prognosis and a fear of impact on patients. ${ }^{2-4,10}$

Simulation as a form of training is rapidly evolving; stepping into a new role allows for greater learning than traditional "apprenticebased' models that are virtually impossible to standardise. ${ }^{11}$ However, outside of courses focusing on technical skills, such as 'advanced life support', simulation is lacking. ${ }^{11}$ The majority of communication skills training in ACP focuses on physicians alone. 9,10 $^{-10}$

The European Association for Palliative Care recommends that non-physicians should help to facilitate ACP conversations. ${ }^{12}$ Such professionals have more time with patients, often in their own homes. $^{13}$

\section{Aims}

Our multidisciplinary communication skills simulation training focused on the complexity of frail, elderly patients and prognostic uncertainties. We aimed to improve participants' knowledge and confidence regarding initiation of ACP discussions and reduce barriers to having these conversations. 


\section{Methods}

We report our methods and results according to guidelines for simulation research. ${ }^{14}$ We conducted nine half-day training sessions between October 2018 and December 2019 where we taught ACP skills through simulation with trained actors. The first two sessions acted as a pilot for the course. We used the title 'The elephant in the room' to capture the difficult nature of conversations.

\section{Ethical approval}

In line with Governance arrangements for research ethics committees, ethical approval was not required for this study.

\section{Setting}

Training sessions were held in hospitals in urban north London. Pilot sessions were hosted at a district general hospital (DGH) and funded by Barnet Community Education Provider Networks (CEPN). Subsequent training sessions were funded by a grant from Health Education England (HEE) and University College London Partners (UCLP), and conducted across three hospitals within the same clinical practice group (CPG). The simulation took place in the education centre of each hospital, using a central room to host the lecture and three smaller rooms for each group. Actors moved between rooms.

\section{Faculty}

The faculty consisted of two specialist registrars in geriatric medicine and two core medical trainees who facilitated the simulation, all of whom had prior local simulation training. Each group of five to six delegates had one facilitator; a further facilitator, either from the faculty or a visiting facilitator, would peer review each other's teaching skills. A specialist palliative care nurse and end-of-life lead facilitated on two occasions and offered input into course content.

\section{Actors}

We used professional actors with healthcare simulation experience. Where possible, we used the same actors for repeated sessions to build relationships and offer feedback. They attended the introductory lecture to gain an understanding of ACP. We briefed actors on delegate experience and background so they could adjust the difficulty of the scenario.

\section{Delegates}

Advertising took place via the hospitals, general practice networks, nursing and therapy leads for the boroughs, and allied healthcare professional (AHP) contacts. We obtained delegate information prior to training including gender, profession, grade and location of work. Delegates were asked about their previous experience and confidence in a pre-course questionnaire using SurveyMonkey (www. surveymonkey.com), with paper copies also available on the day.

\section{Training programme}

Delegates attended a half-day session starting with an introductory lecture before dividing into groups with a range of experiences and professions (Fig 1). Simulator and candidates' introductions were

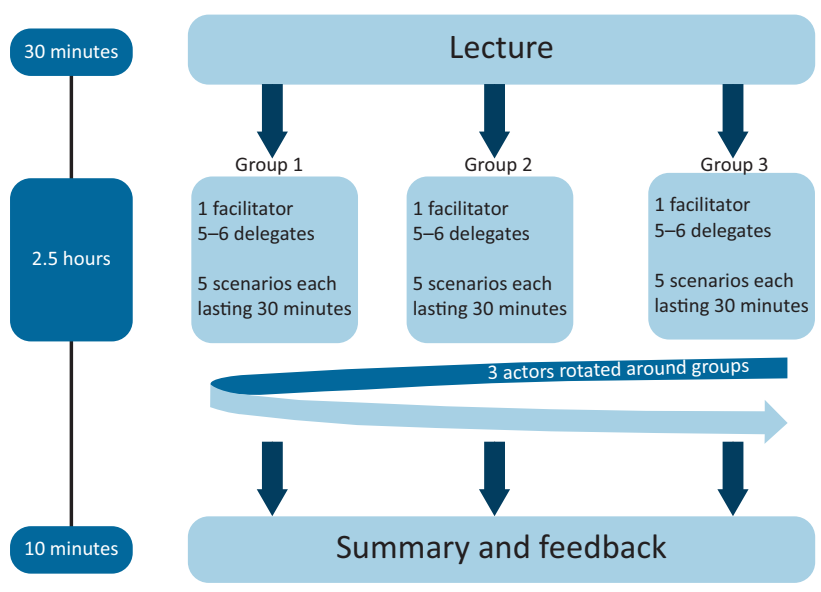

Fig 1. Process of training programme.

held in each group. To allow for last minute cancellations, each course was overbooked. On occasion, this resulted in six delegates in each group. When this occurred, delegates from different backgrounds were paired up; for instance, pairing a junior doctor with palliative care nurse. Feedback on this was positive; confidence was built in a realistic and less daunting manner and this appealed to less experienced members of the group.

Scenarios were written by the faculty, taking inspiration from personal experiences of challenging conversations and mirroring British Geriatrics Society (BGS) guidance on care planning conversations. ${ }^{15}$ We included suggested phrases, attitudes and questions in the actor brief to cover key learning points. Scenarios were adapted based on course feedback; for example, candidates found one scenario too broad, so more specific guidance was created for future sessions.

A debrief after each scenario was facilitated by a faculty member, focusing on the positives of the simulation, any challenges the participant faced and discussion of how to overcome these. Each actor gave one minute of feedback within the role, before stepping outside. Originally, they remained in the room, but we felt they were sometimes too critical: creating a negative learning environment and detracting from specific learning objectives. The small groups then discussed the scenario in more detail enabling delegates to learn from each other's perspectives and experiences. The course concluded with take-home points offered by each participant and shared with the whole group. A handout was provided covering key learning points, 'nuggets' and phrases. Certificates, questionnaires and handouts were branded with our logo to ensure ownership of our work (Fig 2).

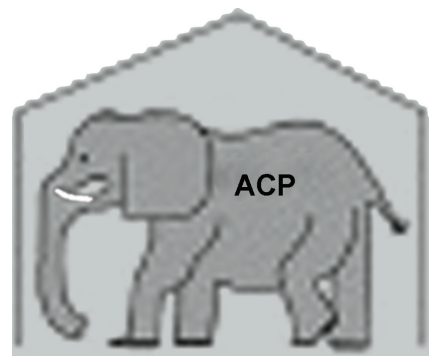

Fig 2. Training programme logo. 
Candidates were encouraged to have discussions that align with the 'Coordinate My Care' ACP tool. Coordinate My Care is an online portal, recognised by the BGS, which allows users to create easily accessible care plans that can be viewed across settings and are situation specific. ${ }^{16}$

\section{Outcome measures}

Pre-course questionnaires were sent to all 132 candidates 4 weeks prior to the course. Post-course questionnaires were given at the end of the training in exchange for a certificate. Follow-up questionnaires were emailed to delegates 3 months after the training. The questionnaires (supplementary material S1) were derived using previously identified barriers to ACP from a local quality improvement project and review of the literature. ${ }^{17}$ They focused on the following outcomes:

$>$ understanding of ACP

$>$ prior ACP training or experience

$>$ confidence with ACP

$>$ barriers to ACP

$>$ current and future practice with regards to ACP

$>$ quality of lecture and scenarios

$>$ feedback on the course.

\section{Course feedback and adaptation}

In the post-course questionnaires, delegates rated the lecture and scenarios from 1 to 5 using a Likert scale and provided comments. The faculty met regularly to act on feedback to improve the subsequent training days.

\section{Results}

\section{Participant demographics}

There were 132 participants across nine training sessions from a wide range of professional backgrounds. They were predominantly women ( $89 \%)$. Nurses from bands 2-8 made up $33 \%$ of candidates; $24 \%$ were general practitioners (GPs) and $30 \%$ were secondary care doctors ranging from foundation year 1 to consultant. Therapists and pharmacists made up $9.5 \%$ of attendees (Table 1).
Table 1. Delegate characteristics

Number of delegates

Total, $\mathbf{n}$ 132

Female, $\mathrm{n}(\%)$

$118(89)$

Male, $n$ (\%)

$14(11)$

Doctors in secondary care (total),

n (\%):

$\begin{array}{ll}\text { Consultants, n (\%) } & 5(4) \\ \text { SpR, n (\%) } & 7(5) \\ \text { SHO, n (\%) } & 22(7) \\ \text { FY1, n (\%) } & 5(4)\end{array}$

GPs, $n(\%)$

$32(24)$

Nurses, $\mathrm{n}(\%)$

$44(33)$

Physiotherapists, $\mathbf{n}(\%)$

Occupational therapists, $\mathrm{n}(\%)$

$4(3)$

Pharmacists, $\mathbf{n}(\%)$

Medical students, $\mathrm{n}(\%)$

Mental health workers, $\mathrm{n}(\%)$

Physician associates, $\mathbf{n}(\%)$

$1(1)$

$\mathrm{FY} 1$ = foundation year 1 doctors; GPs = general practitioners; $\mathrm{SHO}=$ senior house officers; $\mathrm{SpR}=$ specialist registrars.

Participants' knowledge and experience before and after training

One-hundred per cent of applicants completed the pre-course questionnaire. Prior to attending, $77 \%$ of participants felt that they had a full understanding of ACP with $70 \%$ reporting they had a good understanding of when an ACP would be appropriate. Following the course, $100 \%$ felt that they fully understood what was involved in ACP and $100 \%$ understood when it was appropriate to initiate a discussion. Doctors were the most likely to have had prior training.

Confidence improved, with the median confidence score of $3 / 5$ increasing to $4 / 5$ post-course and was sustained 3 months later (Fig 3). Most delegates (88\%) thought that it was the responsibility of all professionals to have ACP discussions, but the majority reported having a single ACP discussion every few months or less.

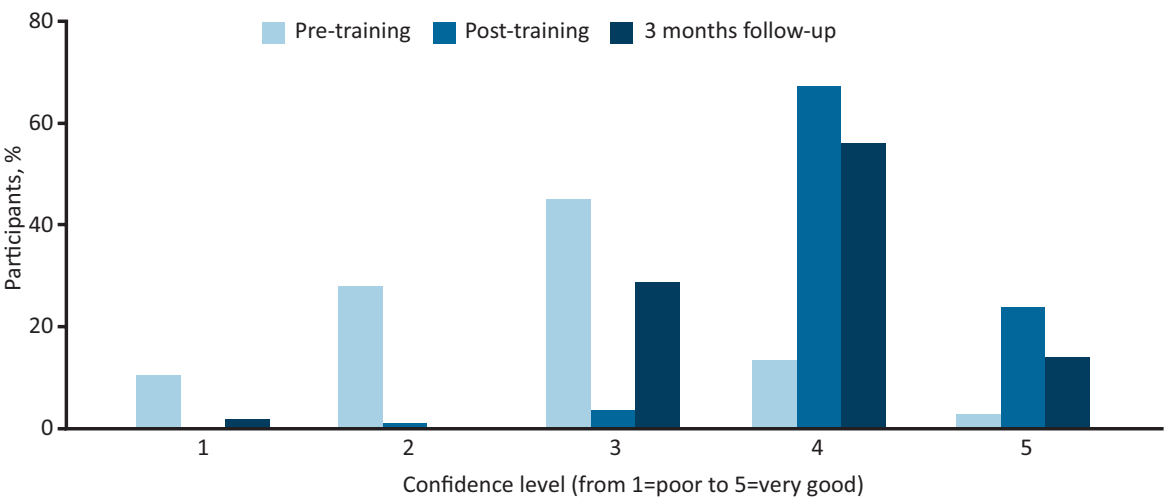

Fig 3. Participant confidence in advance care planning discussions. 
Table 2. Feedback from pre- and post-training and 3-month follow-up questionnaires

\begin{tabular}{|c|c|c|c|c|}
\hline & & $\begin{array}{l}\text { Pre-course, } \\
n=132\end{array}$ & $\begin{array}{l}\text { Immediately } \\
\text { post-course, } \\
n=132\end{array}$ & $\begin{array}{l}3 \text { months } \\
\text { post-course, } \\
n=59\end{array}$ \\
\hline \multirow[t]{2}{*}{ Prior training in $\mathrm{ACP}, \%$} & Yes & 28 & $\mathrm{n} / \mathrm{a}$ & $\mathrm{n} / \mathrm{a}$ \\
\hline & No & 72 & $\mathrm{n} / \mathrm{a}$ & $\mathrm{n} / \mathrm{a}$ \\
\hline \multirow{2}{*}{$\begin{array}{l}\text { Confidence in initiating ACP } \\
\text { (from } 1=\text { poor to } 5=\text { very } \\
\text { good) }\end{array}$} & Mean & 2.8 & 4.1 & 3.8 \\
\hline & Median & 3 & 4 & 4 \\
\hline \multirow{3}{*}{$\begin{array}{l}\text { Understanding of when ACP } \\
\text { is appropriate (timing), \% }\end{array}$} & Yes & 70 & 100 & 100 \\
\hline & No & 25 & 0 & 0 \\
\hline & Unanswered & 5 & 0 & 0 \\
\hline \multirow[t]{6}{*}{ Main barriers to ACP, \% } & Worries about upsetting patients/families & 65 & 24 & 25 \\
\hline & Not enough time & 55 & 56 & 45 \\
\hline & Not feeling confident & 47 & 12 & 15 \\
\hline & Not feeling it is appropriate & 26 & 13 & 17 \\
\hline & Other & 12 & 11 & 19 \\
\hline & Lack of opportunity & 0 & 0 & 31 \\
\hline \multirow{5}{*}{$\begin{array}{l}\text { Frequency of ACP } \\
\text { conversations, } \%\end{array}$} & At least weekly & 24 & $\mathrm{n} / \mathrm{a}$ & 24 \\
\hline & Monthly & 24 & $\mathrm{n} / \mathrm{a}$ & 34 \\
\hline & Every few months & 30 & $\mathrm{n} / \mathrm{a}$ & 25 \\
\hline & Yearly or less & 17 & $\mathrm{n} / \mathrm{a}$ & 9 \\
\hline & Other & 5 & $\mathrm{n} / \mathrm{a}$ & 8 \\
\hline \multirow{7}{*}{$\begin{array}{l}\text { Whose responsibility did } \\
\text { they think it is to have these } \\
\text { conversations, } \%\end{array}$} & GP & 10 & $\mathrm{n} / \mathrm{a}$ & $\mathrm{n} / \mathrm{a}$ \\
\hline & Consultant & 8 & $\mathrm{n} / \mathrm{a}$ & $\mathrm{n} / \mathrm{a}$ \\
\hline & Junior doctor & 6 & $\mathrm{n} / \mathrm{a}$ & $\mathrm{n} / \mathrm{a}$ \\
\hline & Nurse & 0.8 & $\mathrm{n} / \mathrm{a}$ & $\mathrm{n} / \mathrm{a}$ \\
\hline & Any of these & 88 & $n / a$ & $\mathrm{n} / \mathrm{a}$ \\
\hline & Other & 2 & $\mathrm{n} / \mathrm{a}$ & $\mathrm{n} / \mathrm{a}$ \\
\hline & Unanswered & 0.8 & $\mathrm{n} / \mathrm{a}$ & $\mathrm{n} / \mathrm{a}$ \\
\hline \multirow{3}{*}{$\begin{array}{l}\text { Had there been a change in } \\
\text { their practice following this } \\
\text { training, \% }\end{array}$} & Yes & $n / a$ & 98 & 86 \\
\hline & No & $\mathrm{n} / \mathrm{a}$ & 1.5 & 14 \\
\hline & Unanswered & $\mathrm{n} / \mathrm{a}$ & 0.5 & 0 \\
\hline \multirow{2}{*}{$\begin{array}{l}\text { Would they recommend } \\
\text { simulation to teach ACP, \% }\end{array}$} & Yes & $n / a$ & 100 & 100 \\
\hline & No & $\mathrm{n} / \mathrm{a}$ & 0 & 0 \\
\hline \multirow{2}{*}{$\begin{array}{l}\text { Would they recommend the } \\
\text { MDT approach to this ACP } \\
\text { simulation, } \%\end{array}$} & Yes & $n / a$ & 100 & 100 \\
\hline & No & $\mathrm{n} / \mathrm{a}$ & 0 & 0 \\
\hline
\end{tabular}

\section{Barriers to ACP}

Participants highlighted various barriers to initiating discussions (Table 2). The most significant were worrying about upsetting patients/relatives, not having enough time and not feeling confident in initiating discussions. Following the training, there was a $41 \%$ reduction in participants worrying about upsetting the patient/relative and a $35 \%$ reduction in feeling low confidence as a barrier. Time pressure remained an important barrier to having ACP discussions.

\section{Change in practice}

Immediately following training, $98 \%$ of participants stated that they would be more likely to initiate an ACP with a patient. After 3 months, 59 (51\%) participants gave feedback with $86 \%$ stating 
they had a sustained change in practice in ACP because of the course. Following training, participants engaged in ACP discussions more frequently.

\section{Quality of the course}

All participants said they would recommend the simulation course and the multidisciplinary team (MDT) teaching model that was used. The median score for the lecture was $5 / 5$ and the mean score for all the scenarios was $5 / 5$. Participants commented on individual aspects of the course. They appreciated 'matching the scenarios to particular [specialties]' and training that 'pushes you out of your comfort zone in a good way'. The style of simulation was well received: '[The] simulation was surprisingly helpful in preparing me to have ACP conversations with patients' and '[It's] hard to do role play but [it's an] excellent way to learn'.

Responses regarding MDT simulation were very positive with comments such as: 'It is unusual to have a multidisciplinary course but it was managed extremely well and worked' and 'You get to try out new skills and learn from others working in different settings'. One consultant wrote 'You learn so much from others (regardless of level of training or health professional), which rarely happens in real life (or even appraisal / 360 feedback). This kind of MDT is a really rich way to learn in simulated way.' Another commented 'This course should be mandatory.'

\section{Costs of providing the course}

The estimated cost of the course was $£ 80$ per attendee, including the costs for professional actors, facilitators, refreshments and printing, but excluding room hire. With regards to funding this themselves, $35 \%$ of participants said they would, but $62 \%$ would not.

\section{Discussion}

We designed and delivered an MDT simulation to a total of 132 nurses, doctors and AHPs across primary and secondary care, demonstrating improved confidence, improved understanding and a reduction in barriers to having ACP conversations. A sustained change in practice was reported by the majority of candidates following a 3-month 'decay period'. All candidates would recommend this course. Our findings show MDT simulation is an appropriate and desired way to teach ACP.

Findings from the pre-course questionnaire reflect the literature, with only $28 \%$ of delegates having had prior training. Our candidates voluntarily signed up to the course; across the workforce this number may be lower. Inadequate training, prognostic uncertainty and fear of impact on patients are all drivers for a lack of ACP conversations. ${ }^{3,15}$ Following our training, these barriers reduced (Table 2). Candidates reported a lack of time as a consistent barrier. We would argue that, although these conversations cannot be rushed, quality ACP discussions save time in the long run. On a wider scale, it is the role of individual healthcare organisations to allow the time for these conversations to occur.

In keeping with our findings, an American randomised controlled trial found an improvement in self-reported confidence after a palliative care communication skills course. ${ }^{18} \mathrm{~A}$ further study by Braude et al developed a standardised, two-centre, multimodal, interprofessional geriatrics simulation programme. This addressed curriculum areas that are rarely taught formally (such as end-of-life decisions) and it revealed significant improvement of self-reported confidence. $^{19}$

The majority of simulation research focuses on emergency care, surgical or anaesthetic simulation, and are physician-only rather than multidisciplinary. ${ }^{11}$ One study from Australia in 2014 showed a significant improvement in confidence across various domains when teaching $148 \mathrm{GPs}$ and doctors in training on end-of-life communication using a multimodal educational programme. ${ }^{9}$ Another study focusing on patients' satisfaction with anaesthetic residents' communication skills found a statistically significant improvement following simulation. ${ }^{20}$ MDT simulation used in the context of dementia education in the UK demonstrated positive benefits. ${ }^{21}$

Despite team working being at the forefront of geriatric medicine, there is a significant lack of UK-based, multidisciplinary simulation in ACP and to the best of our knowledge, there have not been any previous studies such as ours.

\section{Strengths}

All facilitators were trained in simulation and able to offer support to candidates. Uptake and feedback were similar across both DGHs and one large teaching hospital, suggesting potential for generalisability and reproducibility in a range of settings.

Pre-course questionnaires allowed faculty to understand participants' backgrounds, and subsequently pitch scenarios at the correct level to suit individuals. Pushing candidates too far out of their comfort zones in simulation courses has been noted to have negative effects, which we were conscious to avoid. ${ }^{22}$ Immediate post-course feedback was collected from over $99 \%$ of delegates who attended, and a sustained change in practice was demonstrated with a response rate of $50.8 \%$ after 3 months. This allows for degradation of acquired skills over a period of time, (the 'decay phase') and enables candidates to assess any change in practice within their own clinical environment. ${ }^{23}$ The 3-month follow-up data does not include the most recent simulation day, due to coinciding with the COVID-19 global pandemic.

\section{Limitations}

We collected feedback on whether candidates had changed their practice as a result of the simulation 3 months following the course. However, true generalisability of research findings in simulation studies to everyday practice remains uncertain. ${ }^{24}$ We did not assess the impact the course had on patients, as participants were from diverse medical backgrounds and locations. Further research is needed into the link between ACP simulation and patient benefit.

The training was voluntary; results may be different had it been compulsory. Although overall response was good, not all delegates completed our follow-up survey. There is the risk that only those who had a positive attitude regarding the training responded. A further limitation of the voluntary uptake is that $89 \%(n=118)$ of the delegates were women. Although this may reflect the professional body, as $77 \%$ of the NHS workforce are women, this figure may be more gender-balanced if the course was compulsory. ${ }^{25}$

For this training to be reproducible and standardised, it requires skilled facilitators in advanced communication skills. To ensure the desired balance of MDT members, there should be a designated number of places available for professionals of different 
backgrounds. Within an MDT simulation, less confident members of the group may be more reluctant to contribute to discussions. A previous study that observed a surgical MDT simulation found that senior clinicians were more likely to share information with the group. $^{26}$

\section{Clinical implications}

Throughout the literature, it is recognised that patients are living with and dying from multimorbidity with increasingly complex and unpredictable disease courses within the constraints of a stretched healthcare system. ${ }^{2,6,27}$ In the UK, 51,000 acute beds at any one time are being used by patients over the age of 65 years, with an average of 3.5 hospital admissions in the last year of life. ${ }^{28,29}$ Generalists, including AHPs, will be expected to provide the majority of end-of-life care in both primary and secondary healthcare settings. ${ }^{3,27}$ The Royal College of Physicians, and the Department of Health and Social Care's End of life care strategy, English national dementia strategy and Prime Minister's challenge on dementia acknowledge the importance of quality ACP conversations, promote a move away from 'tick-box' exercises and suggest focus on good communication. ${ }^{30-33}$ The Lancet white paper on ACP states that healthcare professionals need the skills necessary to be able to engage in such open, honest and sensitive conversations. ${ }^{12}$ The BGS recognises the challenging nature of conversations with families who are not ready to accept that a loved one is entering the last stage of life. They highlight that conversations need to be handled with compassion and sensitivity. ${ }^{15}$ However, no formal training is offered to medical students, physicians or AHPs. Our simulation training could fulfil this role.

It has been recognised that ACP should be the role of all healthcare professionals, not just physicians. The multidisciplinary team is at the heart of geriatric medicine yet, Ellis and Sevdalis argue, how can professionals from different backgrounds be expected to work well together when they are trained separately? $?^{34}$ Through our training, we empowered AHPs who have not previously been able to access such training, and created an MDT learning environment, bridging the gap between primary and secondary care.

The majority of patients would prefer to be cared for and die outside of an acute setting. ${ }^{2} \mathrm{~A}$ lack of quality ACP leads to both financial and resource implications for healthcare organisations, together with emotional burden to a family, poor quality of life and significant bereavement reactions. This simulation training appears to be a cost-effective approach to ultimately improving the quality-of-care that patients receive at the end of life.

The global COVID-19 pandemic has reinforced the necessary nature of care planning conversations as healthcare staff face moral injury when being forced to make time critical decisions at a crisis point. We are in the process of establishing an equivalent virtual course, allowing a safe space to nurture confidence and skill with a sensitive ear to the impossible circumstances our colleagues have faced in recent times. We hope to include other members of the MDT in our faculty, including primary care colleagues and will welcome their input on course design to ensure relevance across primary and secondary care.

\section{Conclusion}

We have demonstrated the feasibility and effectiveness of a multidisciplinary ACP simulation course across three regional sites. The simulation was successful in improving participant understanding and confidence, reducing barriers to discussions and facilitating a sustained change in practice 3 months after training. Further research is needed to determine if these benefits translate into improved ACP for patients.

\section{Summary}

\section{What is known?}

Advance care planning (ACP) improves patient and family experience towards the end of life.

Healthcare professionals often feel unprepared for initiating ACP discussions through lack of confidence, prognostic uncertainty and fear of impact on patients.

Multidisciplinary simulation training focusing on ACP communication skills is lacking.

\section{What is the question?}

Is multidisciplinary ACP training an effective way of improving confidence and understanding in the topic, ultimately improving quality and uptake of conversations?

\section{What was found?}

This ACP communication skills training reduces barriers, increases confidence and builds understanding both immediately and following a 3-month 'decay period'.

Candidates are more likely to engage patients and relatives in ACP discussions following on from such training.

We have shown the potential for reproducibility of such a course.

\section{What is the implication for practice now?}

Increasing numbers of patients are dying with multimorbidity and frailty. Generalists across primary and secondary care will be expected to provide the majority of end-of-life care.

Healthcare professionals need to be equipped with the skills to have open, honest and sensitive conversations.

The majority of patients would prefer to be cared for and die outside of an acute setting; this simulation training appears to be a cost-effective approach to ultimately improving the quality of care that patients receive at the end of life.

\section{Supplementary material}

Additional supplementary material may be found in the online version of this article at www.rcpjournals.org/clinmedicine: S1 - Course questionnaires.

S2 - Outline of training programme, content and key learning points; delegate characteristics by training day; and example case vignette for candidate and actor.

\section{Acknowledgements}

We would like to thank Dr Tamar Ish-Horowicz and Rosie Shadat who provided their assistance in running training sessions.

\section{References}

1 Etkind SN, Bone AE, Gomes B, Lovell N, Evans C] et al. How many people will need palliative care in 2040 ? Past trends, future projections and implications for services. BMC Medicine 2017;15:102.

2 National Audit Office. End of life care. NAO, 2008. www.nao.org.uk/ report/end-of-life-care [Accessed 19 November 2019]. 
3 Brighton L], Bristowe K. Communication in palliative care: talking about the end of life, before the end of life. Postgraduate Medical Journal 2016:92:466-70.

4 Harding R, Simms V, Calanzani N et al. If you had less than a year to live, would you want to know? A seven-country European population survey of public preferences for disclosure of poor prognosis. Psycho-Oncology 2013;22:2298-305.

5 Harrison Dening K, King M, Jones L, Vickestaff V, Sampson EL. Advance care planning in dementia: do family carers know the treatment preferences of people with early dementia? PLoS One 2016;11:e0159056. Correction in: PLoS One 2016;11:e0161142.

6 Mullick A, Martin J, Sallnow L. An introduction to advance care planning in practice. BMJ 2013;347:f6064.

7 Harrison Dening K, Jones L, Sampson EL. Preferences for end-of-life care: a nominal group study of people with dementia and their family carers. Palliat Med 2013;27:409-17.

8 Abel J, Pring A, Rich A, Malik T, Verne J. The impact of advance care planning of place of death, a hospice retrospective cohort study. BMJ Support Palliat Care 2013:3:168-73.

9 Detering K, Silvester W, Corke C et al. Teaching general practitioners and doctors-in-training to discuss advance care planning: evaluation of a brief multimodality education programme. BMJ Support Palliat Care 2014:4:313-21.

10 Fulmer T, Escobedo M, Berman A, Koren MJ, Hernandes S. Physicians' views on advance care planning and end-of-life care conversations. Journal of the American Geriatrics Society 2018:66:1201-5

11 Shah A, Carter T, Kuwani T, Sharpe R. Simulation to develop tomorrow's medical registrar. Clin Teach 2013;10:42-6.

12 Rietjens JAC, Sudore RL, Connolly M et al. Definition and recommendations for advance care planning: an international consensus supported by the European Association for Palliative Care. Lancet Oncology 2017;18:543-51.

13 Sævareid TJL, Førde R, Thoresen L et al. Significance of advance care planning in nursing homes: views from patients with cognitive impairment, their next of kin, health personnel, and managers. Clin Interv Aging 2019;14:997-1005.

14 Cheng A, Kessler D, Mackinnon R et al. Reporting guidelines for health care simulation research: Extensions to the CONSORT and STROBE statements. BMJ Simulation and Technology Enhanced Learning 2016;2:51-60.

15 British Geriatrics Society. End of Life Care in Frailty: Advance Care Planning. BGS, 2020. www.bgs.org.uk/resources/end-of-life-care-infrailty-advance-care-planning [Accessed 21 August 2021].

16 Coordinate My Care. How Coordinate My Care works. NHS. www. coordinatemycare.co.uk [Accessed 21 August 2021].

17 Owen L, Steel A. Advanced care planning: What do patients want? Br J Hosp Med (Lond) 2019;80:263-7.

18 Brown CE, Back AL, Ford DW, Kross EK, Downley L. Self-assessment scores improve after simulation-based palliative care communica- tion skill workshops. American Journal of Hospice and Palliative Medicine 2018:35:45-51.

19 Braude P, Reedy G, Dasgupta D, Dimmock V, Jaye P. Evaluation of a simulation training programme for geriatric medicine. Age Ageing 2015;44;677-82.

20 Mitchell JD, Ku C, Wong $\mathrm{V}$ et al. The impact of a resident communication skills curriculum on patients' experiences of care. A\&A Case Rep 2016;6:65-75.

21 Leah V, Combes J, McMillan M, Russell L, McCune K. Experiences of using simulation in dementia education. Nurs Older People 2017:29:27-34

22 Smith AB, Lammers SE. The ethics of simulation. In: Palaganas JC, Maxworthy JC, Epps CA (eds). Defining excellence in simulation programs, First edn. Philadelphia: Wolters Kluwer, 2015;592-6.

23 Blackmore A, Kasfiki EV, Purva M. Simulation-based education to improve communication skills: a systematic review and identification of current best practice. BMJ Simulation and Technology Enhanced Learning 2018:4:159-64.

24 Lamé G, Dixon-Woods M. Using Clincal Simulation to study how to improve quality and safety in healthcare. BMJ Stel 2018;0:1-8.

25 NHS Digital. Narrowing of NHS gender divide but men still the majority in senior roles. NHS, 2018. https://digital.nhs.uk/news-andevents/latest-news/narrowing-of-nhs-gender-divide-but-men-stillthe-majority-in-senior-roles [Accessed 5 January 2020].

26 Cumin D, Skilton C, Weller J. Information transfer in multidisciplinary operating room teams: a simulation-based observational study. BMJ Qual Saf 2017;26:209-16.

27 Grudzen CR, Emlet LL, Kuntz ] et al. EM Talk: communication skills training for emergency medicine patients with serious illness. BMJ Supportive \& Palliative Care 2016;6:219-24.

28 Lyons $P$, Verne J. Pattern of hospital admission in the final year of life. BMJ Supportive \& Palliative Care 2011:1:81-2.

29 The King's Fund. Older people and emergency bed use, exploring variation. The King's Fund, 2012.

30 Royal College of Physicians. Advance care planning: Concise guidance to good practice: Number 12. RCP, 2009.

31 Department of Health. End of Life Care Strategy: Promoting high quality care for all adults at the end of life. DH, 2008.

32 Department of Health. Living well with dementia: A national dementia strategy. DH, 2009.

33 Department of Health. Prime Minister's challenge on dementia: Delivering major improvements in dementia care and research by 2015. DH, 2012

34 Ellis G, Sevdalis N. Understanding and improving multidisciplinary team working in geriatric medicine. Age Ageing 2019;48:498-505.

Address for correspondence: Dr Lucy Owen, Barnet Hospital, Wellhouse Lane, London EN5 3DJ, UK.

Email: lucy.owen2@nhs.net

Twitter: @ACPSimulation 